\title{
Market yourself for the job you want
}

\author{
Tausif Mulla ${ }^{1^{*}}$ \\ ${ }^{1}$ Westford school of Management, UAE
}

Received: October 12, 2017; Accepted: October 16, 2017; Published: October 27, 2017

*Corresponding author: Mr. Tausif Mulla, a faculty at Westford school of Management, UAE.Email:-tausif@westford.org.uk

\begin{abstract}
In today's economy, to get your desired job has become more challenging than it was before. Professionals with even $5+$ years of experience find it difficult to switch to their preferred job. On the flip side, a student who has just graduated from college may become disheartened if s/he doesn't get an interview call from the company of his/her choice. With these ideas, one can stand out from the crowd and get attention of the key people within the industry.
\end{abstract}

\section{Market yourself for the job you want}

As students approach their final semester in college or university the question that makes them restless the most is whether they will get placed or not? If this question isn't answered for them it can do more harm and even result in a depression (Figure1).

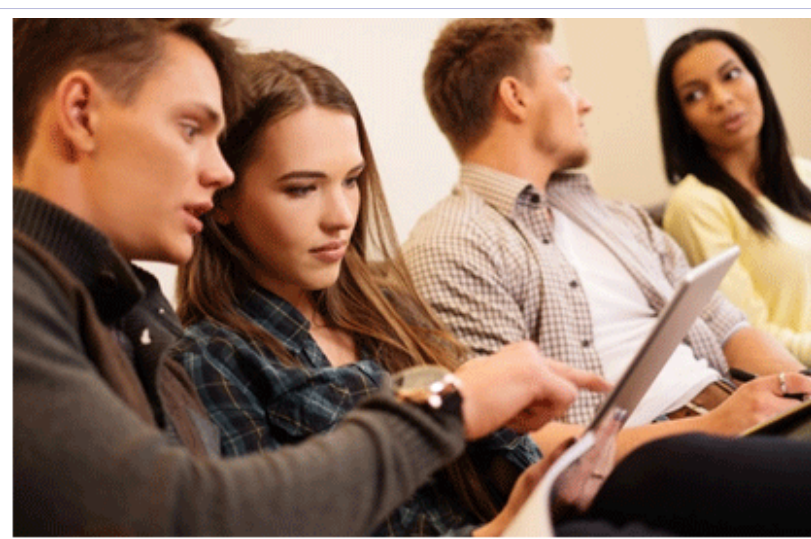

Figure 1

If you are a student in your final semester or a placement head or even an experienced professional and you are looking for opportunities to step into the corporate world this post will be helpful for you. I am writing this post for MBA / Post Graduate students in mind but students from other fields like medical, engineering can also benefit from these ideas.

Since, I am a part of education industry, I see many students struggle to get a good job of their liking. One needs to understand that it's not only "YOU" who is looking for that specific job, but many more prospective students eyeing the same. So how do you stand out from others? I have come up with few ideas that will help you to "MARKET" yourself for the job you deserve.

Before I share the ideas I would like to mention that MBA / Medical / Engineering institutes are NOT a job placement organizations. This is the first thing the students need to erase from their mind. An institute is a platform where students acquire the knowledge and skills needed in the corporate world.

\section{7 ideas that will help you get placement (if you haven't got already)}

\section{Make a Resume to hire}

The first step is preparation. You need to make your resume to apply for a job you are looking for. Make sure you make a CV that stands out from others. Being a fresher you need to portray your achievements in academics and extracurricular activities. Design a CV that demands attention. Have a look at this one from Robby Leonardi.

Pro tip: If you don't have designing skills get help from a friend or pay a freelance designer to make one for you. Make sure your Resume is grammatically correct without spelling mistakes.

Rleonardi.com. (2017). Robby Leonardi | hey@rleonardi.com. [online] Available at: http://www.rleonardi.com/interactive-resume/ [Accessed 17 Oct. 2017].

\section{Register on job portals}

Once you have your CV ready the next step is to upload on all job portals such as Naukri, Bayt, Timesjobs, etc. Make sure to use right keywords in your description as this will make your $\mathrm{CV}$ searchable to the prospective companies. As recruiters go through thousands of CV's in a day, your headline of your profile needs to be very appealing.

\section{Build presence on Social Media channels}

I have rarely come across any student who doesn't have a social media profile. Put social media to use. Be very active on social media platforms like LinkedIn, twitter, Slide share, etc to look for opportunities. 
I simply love LinkedIn as it helps me connect with key people in my industry and keeps me updated about the current market. Make a complete profile with relevant keywords in the headline that catches attention. Check out my profile Tausif Mulla. Also, add groups related to your interest and participate in the ongoing discussion (give your two cents on the current topic) (Figure 2).

\section{Link to this post is here}

In twitter, search with hashtags such as \#job \#Dubai to get relevant results. Also, use twitter to keep yourself abreast with current happenings in the market in your field of interest (Figure $3)$.

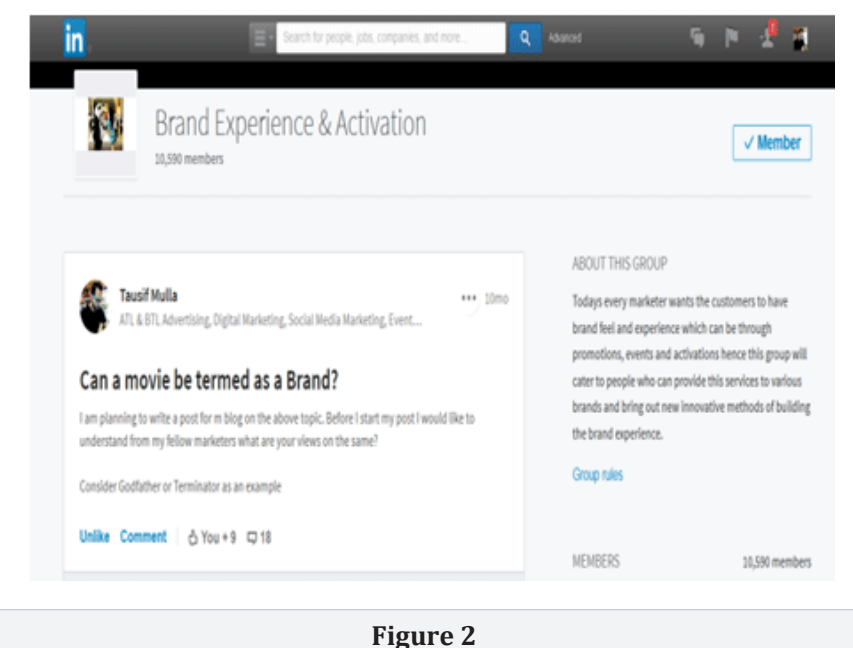

\section{Follow key people on social media}

Once you have an updated social media profile add / follow key people in your industry. I, usually follow people both on LinkedIn and Twitter. Make sure you don't add the same person on Facebook as it is considered more as a personal rather than a professional networking site.

One of the mistakes to avoid is, do not send an immediate message like "Hi, I am looking for a job. Do you have anything

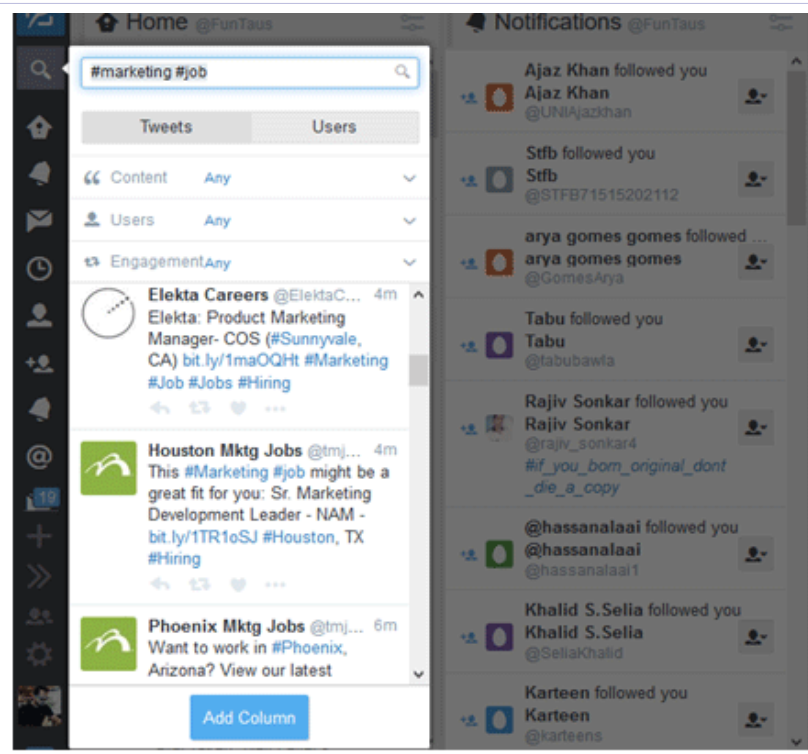

Figure 3

for me?" This is a big NO. Behavior like this turns off a person as it brings out a picture that the recently added person is very unprofessional. Yes, you can mail to the prospective person but it has to be a very polite and professional mail. At this point of time do not rush into asking for openings in the company. Spend some time to go through the person's profile. See what kind of posts he/ she has liked or re tweeted (this will help you gauge the person). Then, message him/her about a certain topic which might be of keen interest to this person.

For example, one of my fellow LinkedIn connection is an avid reader of marketing books. So I will mail him something like this "Hello Mr. Josh, I came across your profile and realized you are an avid reader. I am looking for good books on consumer behavior. Can you suggest few good authors to me?"

Try to keep it simple. If you get a reply then that's your start, but if you don't get a reply then do not bother the person again (Figure 4).

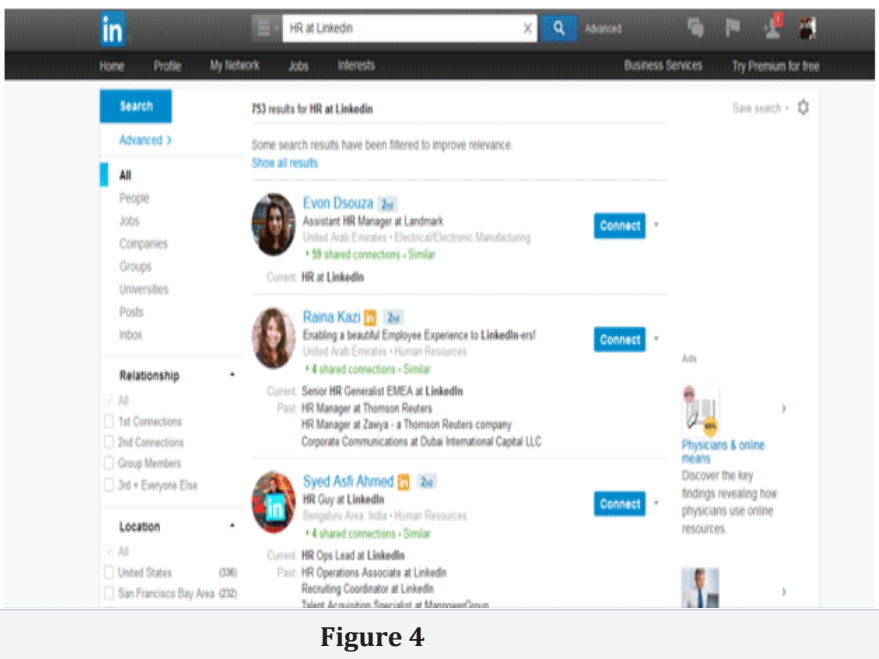


Use the search option both in LinkedIn \& Twitter to search key people like HR Manager at LinkedIn, VP Marketing at Al Futtaim, Finance at Samsung, etc.

\section{Get hooked on to a BLOGGING}

If you haven't already made your own blog, do it asap. Use SEO friendly blogging CMS (Content Management System) tools like WordPress, Blogspot, Wix, etc. Start publishing posts about specific industry, skills, strategy adopted by a company (in your interested field), etc. this will help you in the short term and long term as well. I would suggest write topics related to XYZ brand in the related industry. Whatever you have learn put into practice. You can simply start with SWOT analysis, Porter 5 forces analysis to that specific industry and much more (Figure 5).

MrPrebble's MES Cairo site. (2017). Topic 4 - Marketing. [online] Available at: http://mrprebble.weebly.com/topic-4--marketing.html [Accessed 17 Oct. 2017].

An engineering student can study about challenges in the production of XYZ product and it's analysis. An architecture student can design models of buildings that can conserve energy consumption. Whatever is your field, select a topic and start blogging today.

\section{Don't just talk, show it.}

Once you have your own blog up and running, the next thing is to make an awesome post. This post has to be The BEST one with all the other posts you have published so far. Ideally, this post should showcase your thought process.

Few examples:

1. A finance student will make a list of shares that he feels are good pics because of XYZ....... reasons. He will work on EPS, Debt Equity ratio, etc and make his analysis.

2. A marketing student will work on a strategy for the company he is interested in working for. What is the current strategy, what do you suggest, how will it benefit and so on.

3. A law student can give his two cents on a current suit in court for XYZ brand. What the brand needs to do?

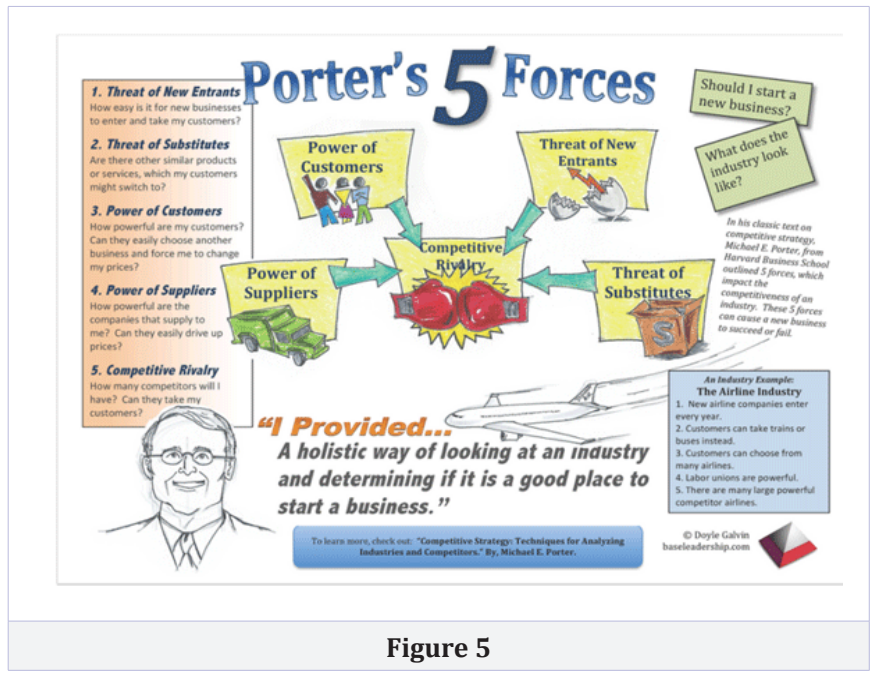

4. An HR student will draft policy for start-up companies (Figure 6,7).

\section{Check her post on Nina4Airbnb}

nina4airbnb. (2017). nina4airbnb. [online] Available at: http://www.nina4airbnb.com/ [Accessed 17 Oct. 2017].

The idea behind these posts is not to show how much you know but to show you are thinking about this company and showing interest to grow the company, that's what will matter here.

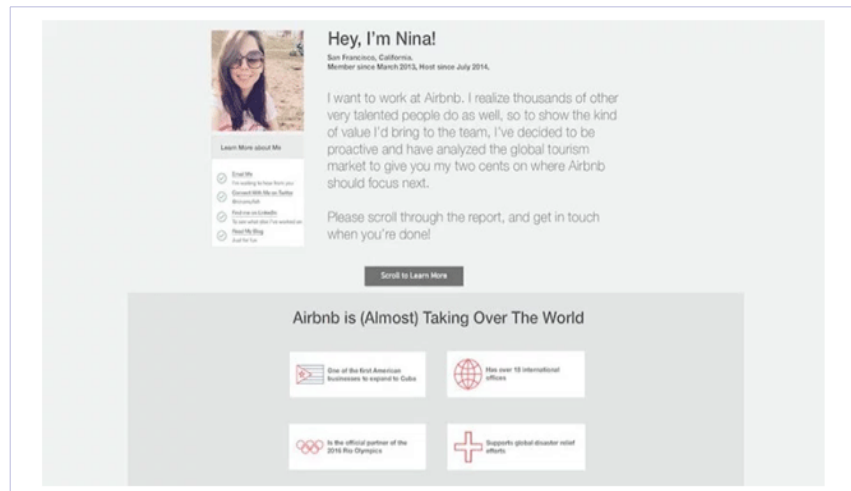

Figure 6

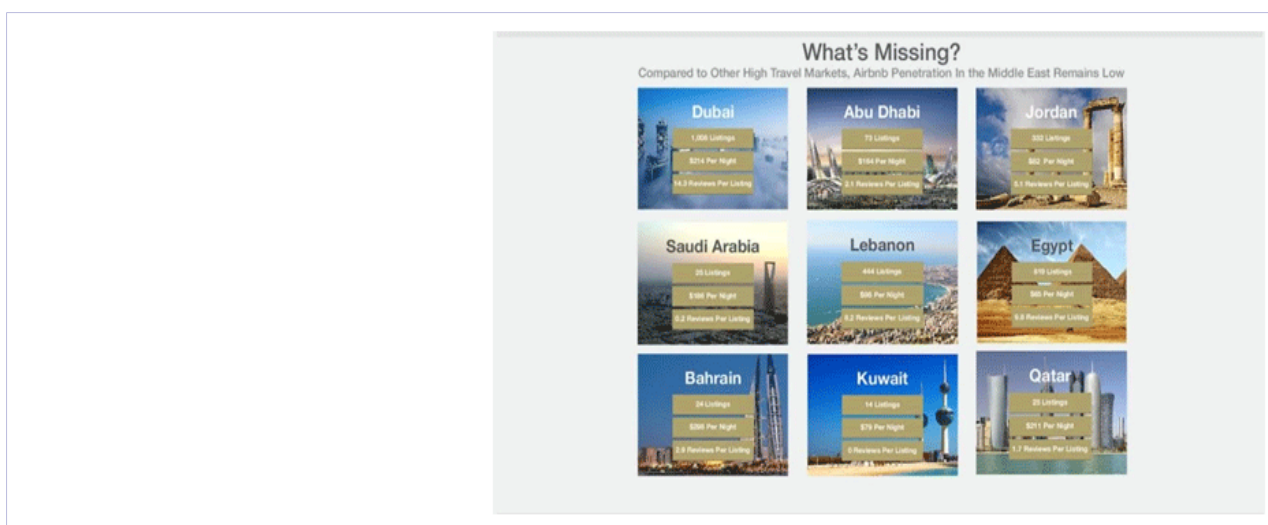

Figure 7 


\section{Sharing is Caring}

In today's world, sharing is caring. Once you have made your best post, now it's time to share with key people. You can share with them on LinkedIn, twitter, emails, etc. Try using Mailchimp tool for emailing to key prospects in the industry. You need to make sure you have a creative headline for the post. One of my posts on LinkedIn is 6 strategies preschools should adopt to boost admissions has become the most searched post for the phrase "strategies for schools". Your headline should give a glimpse of what you want to communicate

When you are emailing your post to a key prospect, be polite. Ask the person to give his VALUABLE feedback on the post that will help you learn more.

Here is an example of how Nina got her awesome post to the founders of Airbnb (Figure 8-10).

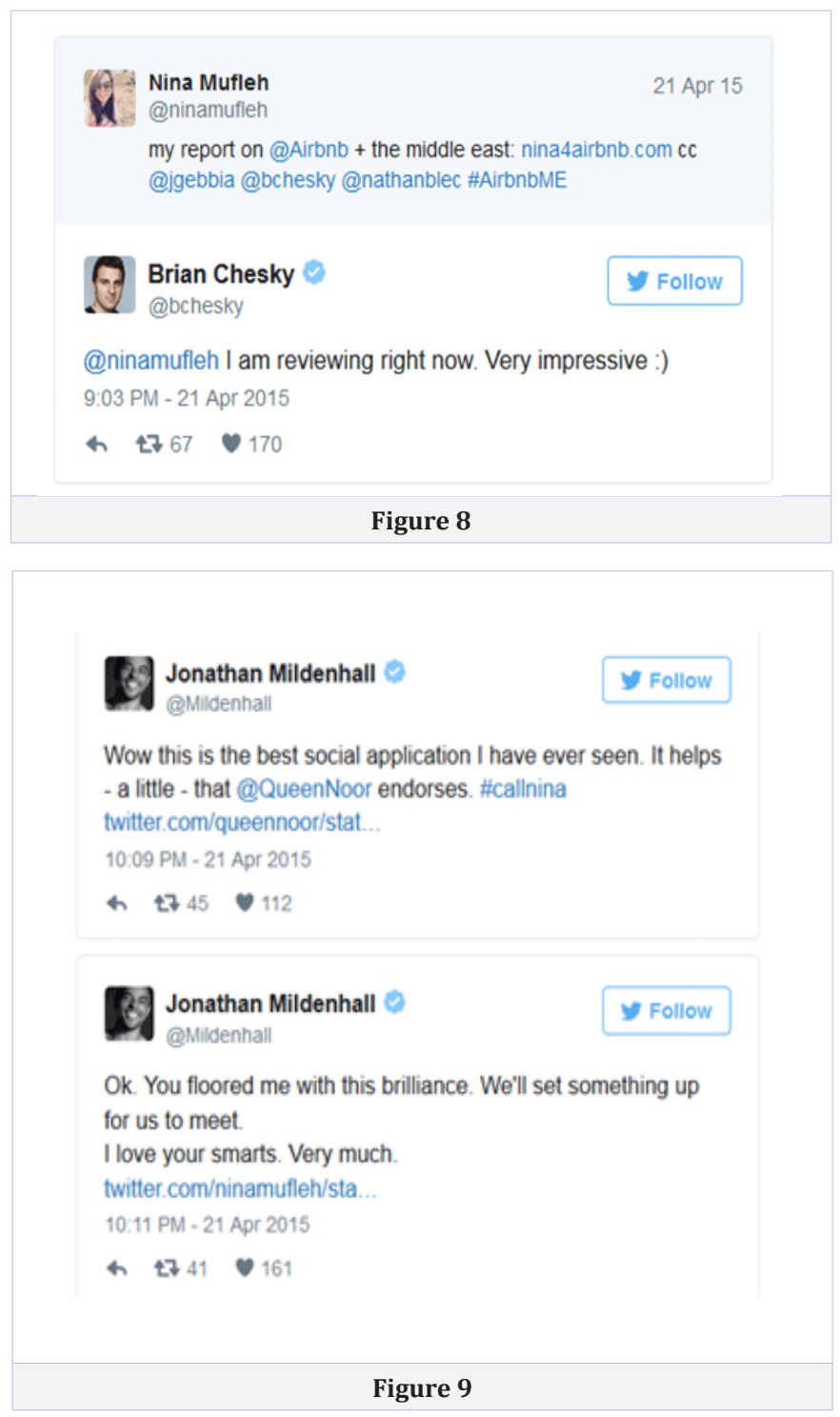

Jonathan Mildenhall

(1)Mildenhall

Follow

Wow this is the best social application I have ever seen. It helps

- a little - that @QueenNoor endorses. \#callnina

twitter.com/queennoor/stat.

10.09 PM - 21 Apr 2015

\& $2745 \bullet 112$

Jonathan Mildenhall

QMildenha!

Ok. You floored me with this brilliance. We'll set something up

for us to meet

I love your smarts. Very much.

twitter.com/ninamufleh/sta..

10:11 PM - 21 Apr 2015

ค $2741 \bullet 161$

Figure 10

Pro tip: Big N0000000 to mass emailing by way of CC'ing or BCC'ing all key prospects in one email. Use MailChimp to make better emails.

Finally, do not be disheartened if you don't get immediate results. Invest some time in these ideas to see positive results. Do share your experience with me if these ideas benefit you to get placement.

\section{About the author}

Tausif Mulla is a Certified Google Educator. At Westford University College, he covers an array of subjects under marketing management. He thoroughly believes in making learning a fun process. You can reach him at tausif@westford.org.uk 